\title{
UM PATRIMÔNIO A SER DESVENDADO: O CEMITÉRIO DA SAUDADE DE CAMPINAS (SP)
}

\section{Halima Alves de Lima Elusta}

Mestrado em Cultura Visual - Faculdade de Artes Visuais - FAV/UFG bolsista do Cnpq

A região de Campinas era, inicialmente, um lugar de repouso no caminho dos bandeirantes que saíam em busca de ouro em Goiás. Com a decadência da atividade mineradora no país, alguns colonos ali se instalaram, dando origem ao Bairro do Mato Grosso das Campinas.

A expansão urbana e econômica se deu com a produção de açúcar na região, que passou a ser chamada de Vila de São Carlos e alcançou proporções de cidade em 1842, quando passou a se chamar Campinas. O progresso da região atraiu diversos profissionais liberais, como médicos, parteiras, advogados e músicos.

Após a década de 1790, a mais próspera para a atividade, a produção açucareira foi sendo reduzida e substituída gradativamente pelo cultivo do café. Os registros sobre os primeiros pés de café na região são confusos, mas oficialmente, segundo Pupo, "o recenseamento de 1805 (e ele era feito no primeiro semestre do ano) já acusava uma produção de quatro arrobas de café produzido em 1804 e consumido todo em Campinas." (1969, p. 141)

Lentamente, a produção de açúcar definhava e em 1860 já estava consolidada a "nova riqueza nascida do solo penoso de Campinas" (PUPO, 1969, p. 144), o café. A mudança no produto de cultivo acabou por influenciar também na organização da cidade.

Esse novo modo de vida da região, com a migração das famílias abastadas, que no período açucareiro viviam nas sedes das fazendas, para a cidade, junto ao crescimento urbano, promove diversas mudanças, como analisou Lapa (1996). São construídos sobrados para residência dos barões, fábricas, surge a iluminação a gás (1875), é fundada a Cia. de Águas e Esgotos (1887), serviços hospitalares e escolas, dentre outros serviços que caracterizam o predomínio da estrutura urbana sobre a rural.

Além disso, "o café trouxe prestígio social e político à elite campineira enriquecida e agraciada com títulos honorários das diversas ordens imperiais" (BADARÓ, 1996, p. 26), elite conhecida hoje como os barões do café. 
Ainda segundo Lapa, conviviam no mesmo espaço duas cidades, uma "racional, objetiva, civilizada que é proposta pela emergência capitalista" em confronto com a outra cidade, colonial. A estrutura urbana e social da cidade foi modificada por três fatores decisivos: a mudança na mão de obra com a chegada dos imigrantes, a construção da estrada de ferro e as epidemias de febre amarela.

A chegada dos imigrantes afetou a estrutura social da cidade, sendo que dentre os profissionais mais qualificados, chegam à região de Campinas alguns artistas-artesãos, com esperança de montar seu próprio negócio e enriquecer rapidamente explorando a elite dessa região próspera. Algumas famílias de marmoristas, principalmente italianas, se estabelecem na cidade e prestam serviços para a burguesia - como as famílias Vélez, Coluccini, Rosada, Ambrust, Lazzeri - na construção de casarões e de monumentos funerários.

Quanto às estradas de ferro, foram inauguradas na segunda metade do século: a Cia. Paulista de Vias Férreas e Fluviais (1872), que ligava Campinas a Jundiaí e entroncava com as linhas de São Paulo Railway, que seguia até o porto de Santos levando a produção campineira de café diretamente para exportação; e a Cia. Mogiana (1875), ligando Campinas ao interior do estado, acompanhando o intinerário do café.

No auge econômico de Campinas chegaram, de 1889 a 1897, mais precisamente nos anos de 1890, 1892, 1896 e 1897, os surtos de febre amarela, sendo decisivas "não apenas para interromper o processo de modernização que vimos estudando, como dar em resultados políticas publicas de saneamento, higiene e saúde pública, como mudanças permanentes na vida urbana, que afetarão toda a população e implicarão em decisivas intervenções cirúrgicas na estrutura e morfologia de Campinas." (LAPA, 1996, p. 259)

Algumas medidas foram tomadas de acordo com os saberes médicos da época, tal como acender fogueiras com ervas aromáticas nas ruas para espantar o mosquito transmissor ${ }^{1}$ da doença; instalação de um Desinfectório Central2; incentivo as pesquisas médicas; mas nada impediu que a população da cidade diminuísse consideravelmente.

1 O mosquito transmissor é o Aedes aegypti

2 O Desinfectório Central era onde ficavam os remédios, médico, forno, estufa e veículos para transporte de cadáveres. (LAPA, 1996, p. 163). 
Após as epidemias, a economia cafeeira retomou sua força e começaram a surgir as grandes indústrias de implementos agrícolas que, com a "crise de 1929, produzindo grande abalo financeiro, especialmente nos setores vinculados ao café, daria novo e decisivo impulso à industrialização no Brasil, cujos reflexos em Campinas, a tornaria uma cidade de economia predominantemente industrial." (BADARÓ, 1996, p. 35)

Com tudo isso, preocupações higienísticas também surgem. O Serviço Sanitário (1892) era implacável, tendo autorização para intervir inclusive nas moradias particulares (LAPA, 1996, p. 190). É nesse contexto de poder absoluto da municipalidade que se deu o processo de secularização dos cemitérios.

Apesar da preocupação com a saúde pública ser anterior às epidemias de febre amarela em Campinas, foi determinante para $\mathrm{O}$ afastamento dos cemitérios dos centros urbanos. A lei ${ }^{3}$ que separava a cidade dos vivos e dos mortos foi colocada em prática especialmente pela divulgação da teoria do miasma, de que os ventos que espalhavam o mau cheiro poderiam causar moléstias na população.

Segundo Lapa, o afastamento dos doentes e dos mortos do centro são conseqüências da "modernidade que chega a esse setor da vida pública (...), o próprio sistema que envolvia a doença, a morte, a condução e o sepultamento do cadáver e a conservação do cemitério era irracional e ineficiente para os padrões burgueses, incompatível com o novo estilo de vida que se implantava." (LAPA, 1996, p. 324)

$\mathrm{Ou}$, como Rodrigues descreveu em seu trabalho sobre as mudanças na história das mentalidades, o homem tende a afastar a morte pois "O pavor de perder a salvação eterna progressivamente se deixou substituir pela esperança de viver mais, de poder protelar a morte, de ser surpreendido por uma descoberta cientifica capaz de cancelá-la" (RODRIGUES, 2001, p. 192). Os ritos fúnebres, o luto, a preocupação com a salvação da alma, gradativamente levam ao desejo de afastar a morte do convívio diário, sendo uma das implicações dessa mudança de mentalidade o afastamento dos mortos pelos vivos.

\footnotetext{
3 "Em complemento a Constituição de Império do Brasil de 25 de março de 1824, a lei de $1^{\circ}$ de outubro de 1828 criava câmara municipais a cada cidade, reservando o Título II, artigo 66, que tratava de Posturas Policiais, no inciso $2^{\circ}$ 'sobre o estabelecimento de Cemitérios fora do recinto dos Templos, conferindo a esse fim com a principal autoridade eclesiástica do lugar"'. (LORETTE, p. 66) in Constituições do Brasil. $4^{\mathrm{a}}$ Ed, São Paulo, Saraiva, 1963, p. 58.
} 
Rezende, analisando as doações de terrenos para construção de cemitérios em São Paulo, constatou que "a estratégia de utilizar a construção de cemitérios para valorização do entorno (século XX), foi mascarada sob uma prática comum antiga no Brasil e no Ocidente católico, que advinha da doação de terrenos para construção de igrejas-cemitérios com o intuito de absolvição dos pecados e salvação da alma, além de prestígio pessoal doador." (2004, p. 07)

Dentre as questões levantadas sobre esse afastamento das necrópoles do centro, o ponto comum é que o cemitério já não era mais aceitável dentro do contexto em que se encontrava a cidade de Campinas. $O$ processo de secularização foi iniciado quando a administração do Cemitério Público passou a ser prioritariamente da Câmara Municipal, apesar de ainda não ser permitido o sepultamento de não-católicos, e foi consolidado com a construção do Cemitério do Fundão (1881).

A nova necrópole, administrada exclusivamente pelo município, deveria, a partir de sua construção, receber os novos sepultamentos dos campineiros, assim como os sepultamentos dos cemitérios existentes na Vila Industrial, que foram para lá transferidos: o Cemitério Público, o Cemitério da Irmandade São Miguel a Almas, o Cemitério do Santíssimo Sacramento e o Cemitério dos Acatólicos.

O novo campo santo deveria ser afastado do centro, sendo para isso nomeada em 1878 uma "comissão especial apoiada por um corpo médico para escolher o local apropriado." (LORETTE, 2003, p. 200). Alguns terrenos foram cogitados para construção do novo cemitério da cidade, pois a situação do Cemitério Público, era insustentável. Então,

optou a Comissão Especial da Câmara pela aquisição, junto a Francisco Abílio de Andrade e Irmãos, de mais ou menos dois alqueires de terras lá para os lados da Capelinha do Fundão (1879), cujo nome é eloqüente na indicação da distância em que ficava da cidade e onde se foi construindo o novo cemitério, cerca de três quilômetros, que teria começado a funcionar em 1881, e para onde, entre 1888/1889, foram exumados e transferidos os restos mortais dos que jaziam nos outros cemitérios da Vila Industrial, com autorização do bispo diocesano de São Paulo. (LAPA, 1996, p. 332)

Segundo Lapa, o terreno escolhido pertencia Abílio de Andrade e sua família. Esta mesma informação é encontrada no trabalho de Lorette (LORETTE, 2003, p. 2001):

Em sessão de 28 de julho de 1879, os vereadores Jorge Miranda e Joaquim Teixeira Nogueira e Almeida propuseram à Câmara que procedesse a desapropriação, amigável ou judicial, do terreno que havia escolhido e que pertenci a Francisco Abílio de Andrade, irmã e outros, situado nas imediações da capelinha de Santa Cruz do Fundão, às margens da antiga estrada de Valinhos, distando da cidade cerca 
de três quilômetros, e com uma área de dois alqueires, aproximadamente. Lá, deveriam ficar reunidos todos os cemitérios existentes e ao que futuramente se fundassem.

Algumas fontes, inclusive o site da Prefeitura da Campinas, informam que parte do terreno do cemitério foi doado por Joaquim Ferreira Penteado ${ }^{4}$, o Barão de Itatiba, mas de acordo com os documento encontrados na pesquisa de Lorette, Ferreira Penteado, pediu para "levantar um jazigo em seu próprio terreno, unido ao Cemitério" do Fundão deixando o jazigo-capela 5 à disposição do público para missas e solenidades religiosas. (2003, p. 203) A Câmara que já cogitava a construção de uma capela aceitou. A capela foi projeta por Ramos de Azevedo 6 , realizada em julho de 1882, sendo refeita e ampliada no começo do século XX por outros construtores.

O terreno ao lado do jazigo-capela foi doado ou adquirido pela prefeitura, junto ao Barão de Itatiba, por isso a atribuição de algumas fontes como sendo ele o doador das terras do cemitério. Hoje a capela encontra-se bem no centro da necrópole, conforme podemos observar no mapa de quadras do cemitério, que sugere que essa segunda parte do atual tenha sido estrategicamente medida.

A primeira capela possuía a fachada neoclássica ${ }^{7}$ e era decorada com estátuas de mármore, mas após a reforma passou a ser um exemplo de monumento art déco (fig 01) A sua fachada adota formas simétricas, com os eixos verticais e horizontais em formato de cruz latina. Está composta por

${ }^{4}$ Joaquim Ferreira Penteado (1808 - 1884), nascido em 1808 na Vila de São Roque, foi um rico fazendeiro da região, sempre lembrado por seu caráter humanitário. Em 1822 recebeu do Governo Imperial a condecoração de Comendador da Imperial Ordem da Rosa e o título de Barão de Itatiba.

${ }^{5}$ Jazigo-Capela "trata-se de uma capela pequena, construída em cemitério ao ar livre, cuja sepultura reúne todos os mortos de uma mesma família”(...) “de uma maneira geral, está imbuída de características provenientes do ecletismo” (BORGES, 2002, p. 176)

${ }^{6}$ Francisco de Paula Ramos de Azevedo (1851 - 1928) campineiro, nas décadas de 1860 e 1870 freqüenta o curso de artilharia da Escola militar do Rio de Janeiro. Precisa interromper os estudos para trabalhar na construção civil, participando da construção da Ferrovia Mogiana, em Campinas. Retoma os estudos e muda-se para Bélgica (1875-1878) para cursar engenharia artística na Université de Gand, quando desenvolve o gosto pelo ecletismo que será característica principal de sua obra aqui no Brasil.

Ao retornar a Campinas (1879), retomando a amizade com o engenheiro civil Francisco de Paula Souza, trabalham em conjunto em algumas obras. Nesse período de 1878 a 1886, realiza projetos para diversas construções na cidade, como o Mercado municipal, o Matadouro.

Segundo descrição de Lorette, p 207

8 Art déco na arte funerária em geral caracteriza os túmulos pelas "linhas geométricas simplificadas, revestidas com granito ou mármore cinza e com poucas peças escultóricas de bronze e poucos atributos culturais" (BORGES, 2002, p. 292) 
elementos geométricos na parte inferior e outras arredondadas na parte superior do telhado. Toda a parte superior é ornamentada com temas florais e abstratos. Não existem janelas, apenas três pequenas aberturas na fachada do jazigo-capela.

Observando a lateral da capela, percebemos seu comprimento alongado, que aparenta existir um espaço amplo no interior, que infelizmente não é possível conhecer, pois a porta de metal com uma cruz latina cercada de ramos de flores, permanece constantemente fechada. A proporção do jazigo-capela se destaca dentro do seu entorno, espaço destinado ao Cemitério do Santíssimo Sacramento e da Saudade.

A secularização possibilitou que o cemitério passasse a ser uma "instituição cultural, além de religiosa", um típico exemplo de cemitério burguês do final do século XVIII e começo do século XIX, uma miniatura arquitetônica da cidade dos vivos. (BORGES, 2002, p.130). A crença do período colonial de salvação da alma com o sepultamento ad sanctos ${ }^{9}$ é gradativamente substituída pelo costume da burguesia de eternizar sua importância e grandeza com monumentos funerários que representassem o que foram em vida. Portanto, além de ser um local de importância religiosa, o cemitério do século XIX é um lugar de memória e de arte.

O Cemitério do Fundão, passa então a se chamar Cemitério da Saudade e abriga túmulos repletos de esculturas simbólicas, epitáfios com relatos sobre a existência das personagens campineiras, além de bustos, fotografias e outros artigos funerários que podem ser considerados objetos artísticos e fonte de pesquisa histórica.

Após retomar o espaço histórico dos mortos em Campinas, fica mais fácil compreender a organização do Cemitério da Saudade, observando seu mapa de quadras. O cemitério possui uma área total de $181.500 \mathrm{~m}^{2}$ (7,5 alqueires), cerca de 30 mil sepulturas espalhadas pelas 72 quadras ${ }^{10}$. Existem quatro portões além da entrada principal e ele está divido por avenidas na horizontal e alamedas na vertical que definem o traçado quadriculado das quadras.

Caminhando a pé pela entrada principal logo nos deparamos com o prédio da administração, projetado por Ramos de Azevedo. A fachada

\footnotetext{
9 Ad sanctos - costume de inumação no interior das igrejas. De acordo com a crença católica, a proximidade do túmulo ao altar definia também a proximidade da alma ao divino.

${ }^{10}$ Dados existentes no mapa de quadras do cemitério encontrado na administração e editado pela Setec, datado de 2003.
} 
dessa entrada principal do cemitério também é atribuída, sem comprovação, ao arquiteto. É uma construção horizontal com um portão principal ao centro e duas portas laterais menores, é uma composição simétrica, possui colunas neoclássicas e encostadas nas paredes laterais (fig. 2).

Os antigos cemitérios que foram transferidos para o Saudade possuíam muros delimitando a área de cada irmandade, o que hoje já não existe. Hoje é possível percebê-los pelas quadras assinaladas no mapa e pela existência das capelas de cada irmandade.

Seguindo a planta do cemitério, para o lado leste da entrada principal, logo nos deparamos com o Cemitério da Irmandade São Miguel e Almas, composta de quatro quadras e uma capela, conhecido atualmente como Cemitério do Toninho, onde o prefeito assassinado de Campinas foi sepultado em 2001. Este foi um dos campos santos transferidos a partir de 1881.

Não existe nenhuma separação física, como muro ou grade, para que cheguemos ao próximo cemitério, o da Venerável Ordem Terceira do Carmo. Não existem referências sobre a existência deste cemitério antes da construção do Cemitério da Saudade, o que sugere que tenha sido construído a partir de 1881.

Seguindo ainda para o lado leste do Cemitério da Saudade, encontramos um pequeno muro que não mede mais de um metro de altura, com uma escada de poucos degraus que define os limites do Cemitério Cura D'Ars, um dos primeiros a ser construído no local, reservado às vítimas das epidemias de febre amarela da década de 1890. Este cemitério foi criado para sepultamento dos campineiros enfermos que antes eram depositados nos lazaretos. Todavia, não existe evidência alguma de que os corpos sepultados anteriormente nos lazaretos tenham sido transferidos para esse cemitério, especialmente pelo costume de incinerar esses locais "contaminados" após a desativação. Mas, após a inauguração do cemitério municipal, as inumações dos doentes passaram a ser neste local. Este cemitério possui monumentos mais simples e fica um pouco abaixo do nível do entorno.

Retornando à entrada e seguindo a avenida principal, cujo nome, Avenida das Palmeiras, define bem sua principal característica, podemos perceber no caminho os belíssimos monumentos de personagens importantes da história campineira, como os da Família Penteado, dos Barões Geraldo de Resende e Atibaia, entre outros. Esses túmulos foram 
escolhidos pela localização privilegiada na avenida principal para demonstrar a importância das pessoas ali sepultadas.

Bem no centro da Avenida das Palmeiras, encontra-se a Capela da Família Ferreira Penteado e, ao seu lado, o Cemitério da Irmandade do Santíssimo Sacramento, que possui vinte e nove quadras de tamanhos diferentes, cujo limite é o jazigo-capela da Família Ferreira Penteado.

Uma característica marcante desse cemitério é a necessidade do espectador ter que voltar seu olhar para cima, pois os monumentos que resistiram à depredação e aos furtos são verticais. A grande maioria dos túmulos da quadra número um foram construídas de mármore branco, o Carrara.

Contrastando com essa primeira, a segunda quadra, logo ao lado, está quase vazia, com muito espaço cimentado no chão. No período de um ano, desde que estes túmulos começaram a ser observados por nós, verificamos que muitos já não existem mais. Vê-se uma movimentação de pessoas trabalhando, funcionários que removem os túmulos antigos e constroem novos, normalmente de granito. Essa construção de novos túmulos mostra que as sepulturas, teoricamente perpétuas e tombadas pelo Condepacc ${ }^{11}$, estão sendo revendidas irregularmente e o patrimônio cultural da cidade está sendo perdido.

O restante das quadras são o que chamamos de Cemitério da Saudade, que pertencia à prefeitura da cidade, sem irmandade definida. Fica clara então a diferenciação dos antigos cemitérios religiosos e particulares da cidade que a partir de 1881 foram transferidos para este cemitério secularizado. Cada um deles possui sua própria capela e por vezes os estilos e materiais dos túmulos são diferentes.

O Cemitério da Saudade, assim como os demais cemitérios convencionais do Brasil, construídos no final do século XVIII e começo do século XIX, que "adotaram maneiras próprias para que os valores burgueses ficassem registrados no seu partido urbanístico e arquitetônico. Por meio de normas peculiares, as construções eram dotadas de funcionalidade, de valor artístico e simbólico, pretendendo sempre cultuar a memória do morto como ser social.” (BORGES, 2002, p. 282/283)

Portanto esse cemitério é parte do patrimônio histórico e cultural da cidade de Campinas, infelizmente desvalorizado e pouco conhecido pela

\footnotetext{
${ }_{11}$ Tombamento em 11/12/2003, Resolução de nº53 de 25 de novembro de 2004.
} 
própria população da cidade. É necessário voltar o olhar para este espaço como fonte de pesquisa e também para sua preservação.

\section{Bibliografia}

BADARÓ, Ricardo de Souza Campos. Campinas, o despontar da modernidade. Área de Publicações do Centro de Memória da Unicamp - CMU, Campinas, 1996.

BORGES, Maria Elizia. Arte funerária no Brasil (1890-1983): oficio de marmoristas italianos em Ribeirão Preto. Belo Horizonte: C/Arte, 2002.

LAPA, José Roberto do Amaral. A cidade - os cantos e os antros - Campinas 1850 - 1900. Edusp: São Paulo, 1996.

LORETTE, Antonio Carlos Rodrigues. Cemitério em Campinas: a transformação do espaço para sepultamento (1753-1881). Mestrado em urbanismo, PUC-Campinas, Campinas, 2001.

PUPO, Celso Maria de Mello. Campinas, seu berço e juventude. Campinas: Publicações da Academia Campinense de Letras, 1969.

REZENDE, Eduardo Coelho Morgado. O céu aberto na terra: umaleitura dos cemitérios de São Paulo na geografia urbana. Dissertação de mestrado em Geografia Humana, USP, São Paulo, 2004.

RODRIGUES, José Carlos. Tabu de morte. Rio de Janeiro: Achiamé, 1983. 


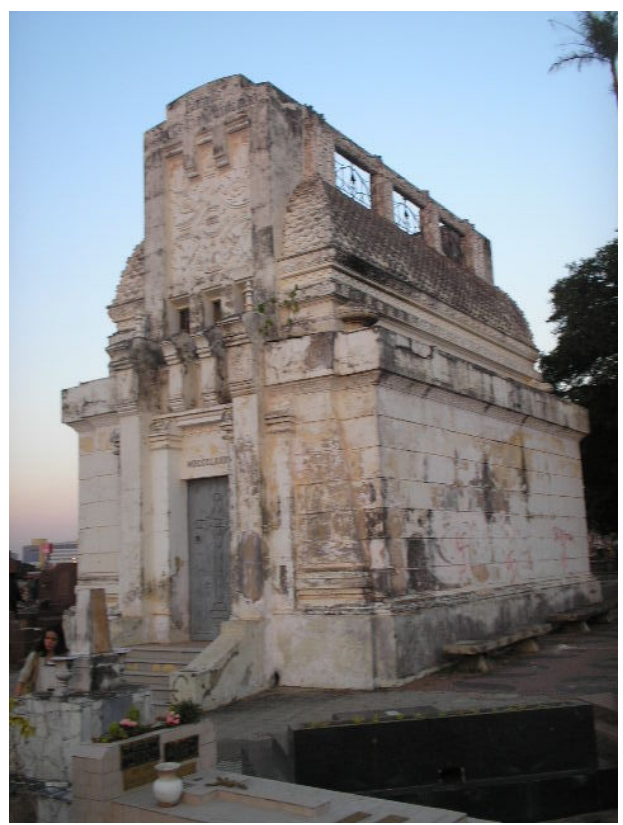

Figura 1 - Vista diagonal da Capela da Família Ferreira Penteado, Halima Elusta, 2006.

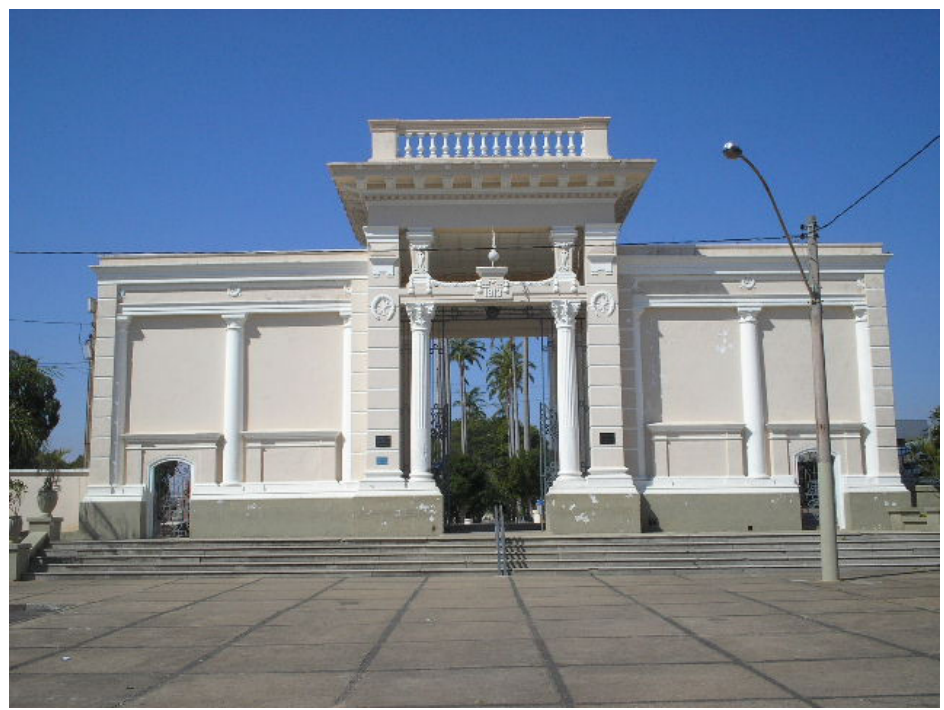

Figura 2 - Entrada do Cemitério da Saudade, Halima Elusta, 2006. 